\title{
The Parasitological Pursuit: Crossing Species and Disciplinary Boundaries with Calvin W. Schwabe and the Echinococcus Tapeworm, 1956-1975
}

\section{Rachel Mason Dentinger}

In August 1964, on a sheep ranch in the San Joaquin valley in California, a five-year-old boy, known to us only as 'J.O.', leapt to the ground from the back of a flatbed truck. Though the 0.75 -metre drop should have been trivial, J.O. fell to the ground in tears, collapsing in sudden abdominal pain. By evening he was admitted to the hospital with suspected appendicitis. Instead, doctors discovered that J.O.'s liver and lungs were strewn with cysts, varying in diameter from 2 to $10 \mathrm{~cm}$. His leap had ruptured a cyst in his liver, causing pain and a subsequent reaction as its contents spread inside his body. ${ }^{1}$

The cysts that J.O.'s doctors removed that night were larval bodies of the tapeworm Echinococcus granulosus, which were bequeathed to him by one of the many dogs that lived on his family's ranch. His father, Salvador, like other sheep ranchers of Basque descent, kept a range of dogs: from his favourite, Blue, who was treated as a pet, to the sheepdogs Murico and Pancho, who were treated as workers. ${ }^{2}$ As a child roaming the ranch, J.O. might have tussled with any of these dogs; and, for his part, the dog would have responded affectionately by licking the

\footnotetext{
${ }^{1}$ Araujo et al. (1975) p. 298.

${ }^{2}$ These are the names of dogs on the ranch in 1968 , but they illustrate the importance granted to the dogs by the humans, including Araujo et al. (1975), which listed their names, ages and sexes.
}

(C) The Author(s) 2018

A. Woods et al., Animals and the Shaping of Modern Medicine, Medicine and Biomedical Sciences in Modern History, https://doi.org/10.1007/978-3-319-64337-3_5 
child's face. Since the dog's faeces were likely teeming with the tapeworm's eggs, which he had picked up from eating the flesh of diseased sheep on the ranch, so too was his tongue. And in this commonplace domestic interaction, E. granulosus entered J.O.'s body.

The child's infection reached a crisis point at a time when parasitologists, physicians and epidemiologists were not yet convinced that E. granulosus was an endemic resident of the USA. Instead, many believed that this particular parasite was only an import, an infection that immigrants contracted prior to their arrival. However, cases like J.O.'s-infections in people who had been born in the USA and never travelled outside of it-belied this assumption. ${ }^{3}$ The case of J.O. and a subsequent study of his family soon became part of a multifaceted investigation into E. granulosus, a large-scale study conducted by American veterinary epidemiologist Calvin W. Schwabe with the aim of understanding how the parasite could be transmitted and sustained in the USA, below the radar of the public health system.

A pivotal figure in this volume, Schwabe was one of the original formulators of One Medicine (OM), a later twentieth-century philosophy predicated on the idea that human and non-human health were intimately connected and therefore most effectively studied in tandem. As this chapter will demonstrate, this philosophy grew from, and was reflected in, his efforts to understand E. granulosus as a biological and a cultural phenomenon, through the application of scientific methods that together transgressed multiple disciplinary boundaries. His investigations into how the parasitic animal both shaped and was shaped by the relationships between other animals in the wild, on the farm and within the homes of Basque sheep farmers illuminate his multidisciplinary ethos, but also demonstrate his rootedness in a parasitological tradition that placed the parasite at the centre of the study, treating it as an animal as biologically interesting and important as its host. For Schwabe, the human, wild and domestic animals that E. granulosus infected were not victims but hosts, which interacted with their tapeworm partner in a number of ecologically complex ways.

This view of parasites as animals unsettled the prevailing dichotomy between humans and other animals, and between the biological study of animal life and the medical study of animals as shapers of human health. It drew on older traditions, those explored in Chapters 2 and 3, which were developed in the context of nineteenth-century zoology, natural history, and agricultural and veterinary research, and which

\footnotetext{
${ }^{3}$ On shifting assumptions about infection on US soil, see Brooks et al. (1959).
} 
saw knowledge about animal and human bodies and diseases as mutually informative. But it also gained strength from post-Second-World-War efforts to promote international health, which, as described in Chapter 4, brought the health of humans and animals together in new and important ways. In tracking the parasite that drew Schwabe onward and led him between different species and domains, this chapter demonstrates both the continuity, and the continually evolving nature and circumstances, of cross-species approaches to health, showing how this was done, robustly and productively, through cross-disciplinary tools and alliances. It will follow Schwabe's lead in placing E. granulosus at the centre of historical analysis, and approaching it as an animal that merits historical investigation in its own right and for its own sake, ${ }^{4}$ not simply on account of the threat that it posed to human health-which is the role most often awarded these organisms by medical practitioners and medical historians alike. ${ }^{5}$

In exploring how Schwabe studied, tracked and conceptualized the parasite, this chapter also throws new light on his life and work. As described in Chapter 6, the movement for OM which Schwabe spearheaded would not begin to gather momentum until the last decades of the century. However, from 1964, when Schwabe published his first monograph, Veterinary Medicine and Human Health (VMHH), he was building an argument and a body of practical recommendations for the joint practice of human-non-human medicine, which would become the basis of $\mathrm{OM}$ and its later incarnation, the twenty-first-century One Health $(\mathrm{OH})$ movement, which adopted Schwabe as its figurehead. ${ }^{6}$ When discussing his role as 'founding father' of OM and the field of veterinary epidemiology, commentators tend to focus attention mainly on the years following 1974, when Schwabe largely left the laboratory behind and launched a new epidemiological phase of his career, working as a global health advocate for the World Health Organization (WHO), and as an academic and administrative bridge between medical and veterinary training. This has elided important aspects of his earlier,

\footnotetext{
${ }^{4}$ Benson (2011) p. 5.

${ }^{5}$ For further reading on this role and others assigned to animals in the history of medicine, see Appendix: Annotated Bibliography of Animals in the History of Medicine.

${ }^{6}$ As discussed in Chapter 6, OM was renamed $\mathrm{OH}$ closer to the turn of the century, when a series of worrying zoonotic pandemics (e.g. SARS and avian influenza) vividly demonstrated just how intimate the human-non-human connection really is.
} 
parasitological experience, which, as this chapter demonstrates, was crucial to his story and to the wider histories of $\mathrm{OM}$ and $\mathrm{OH}$.

To begin, I reconstruct Schwabe's first decade of research on E. granulosus at the American University of Beirut (AUB), placing his work theoretically and practically in the disciplinary context of parasitology, showing how he drew from and elaborated on this tradition in order to understand the tapeworm, which was widespread among the human and non-human inhabitants of Beirut. Through this work, E. granulosus occupied multiple roles, far beyond that of the circumscribed infective agent'. It served as a point of comparison in understanding the biology of other animals, ${ }^{7}$ as an ally in the pursuit of scientific knowledge in the laboratory, ${ }^{8}$ and a symbiont with the ability to both respond adaptively to and shape its own environment - in this case, the bodies of the larger animals that hosted it, and the careers of the researchers whose lives' work revolved around it.

In the second section I show how the parasite drew Schwabe out of the laboratory and into the city, where its dynamic movement between the host populations of Beirut, including both human and non-human animals, intrigued and challenged parasitologists. Schwabe responded to the parasite's challenge by developing a new mode of parasitological pursuit, observing how biological and sociocultural factors interacted to provide new opportunities for E. granulosus. Finally, in the third section, I follow Schwabe as he transplanted this new culturally sensitive epidemiology to a new geography, moving from Beirut to California. At this point I return to the Basque sheep farm, where a new and as-yet-undetected epicentre of E. granulosus had developed. Schwabe, with his parasitological background, a methodological arsenal developed in Beirut, and his special sensitivity to the parasite that he had tracked for decades, quickly detected its presence and resumed his pursuit of it in this new environment. In this phase of his career, Schwabe adopted more epidemiological and programmatic emphases. Yet this period did not represent a dramatic divergence from his earlier work, and his commitment to E. granulosus persisted. Further, it is in this final transition that we see most vividly how each elaboration of his career-from laboratory to population, from Beirut to Kenya to California, from veterinary medicine to OM-took shape in response to the movement of this miniscule, parasitic animal.

\footnotetext{
${ }^{7}$ See Chapter 2.

${ }^{8}$ See Chapter 3.
} 


\subsection{Pursuing Echinococcus in Beirut: The Parasitology of Calvin W. Schwabe}

In 1956, Calvin Schwabe moved his young family from Boston, Massachusetts, to Beirut, Lebanon. He had just completed his doctorate of science in parasitology and public health at Harvard University, as well as a postdoctoral fellowship, funded by the National Institutes of Health $(\mathrm{NIH})$, investigating the physiology of a rodent parasite. His qualifications did not stop there: with a doctor of veterinary medicine, a master of public health and a master of science in zoology, Schwabe was well prepared for his new post as the associate professor of parasitology and chairman of the Department of Parasitology at AUB, where he would rapidly launch a research programme focused on the tapeworm parasite E. granulosus. ${ }^{9}$

Hoping to 'hit the ground running', Schwabe had already begun to consider possible research subjects before leaving Boston. ${ }^{10} \mathrm{He}$ knew that E. granulosus - which constituted a 'medical and economic problem on all inhabited continents'll —was widespread in Beirut and wielded a significant impact on human health. The life cycle of this parasite had already been worked out. It had a diminutive worm stage that lived mostly in

\footnotetext{
${ }^{9} \mathrm{MS}$ in zoology from the University of Hawaii, 1950; DVM, Auburn University (Alabama), 1954; and MPH in tropical public health from Harvard, 1955. Schwabe (2004) p. 208. Schwabe later recalled that he had never once attended a class on parasitology per se. Schwabe (n.d.) pp. 153, 186. However, his sequence of degrees, in combination with his clinical, agricultural and laboratory research experience in parasitology, qualified him for this position. While a biology undergraduate at Virginia Polytechnic Institute, he became an 'Assistant in Parasitology' at the Virginia Agricultural Experimentation Station, an experience that he repeatedly referred to as the foundation of his parasitological training. Indeed, the importance of this undergraduate job to him is evident in that he continued to list it on his CV for the duration of his career. His Master's research project at the University of Hawaii focused on an agricultural parasite of chickens (Schwabe 1951, 1957). Then, from 1950 to 1953, while earning his DVM at Auburn, he worked again as a parasitologist, this time in a US Department of Agriculture laboratory. After leaving Auburn for Boston, he became a staff affiliate in parasitology and zoonoses at Angell Memorial Hospital. 'Curriculum Vitae' (n.d.).

${ }^{10}$ Schwabe (n.d.) pp. 212, 336.

${ }^{11}$ Schwabe (1964) p. 208.
} 
the guts of canines (the 'definitive host'). ${ }^{12}$ Its eggs exited canine bodies via their faeces, to enter the bodies of humans and other animals that came into contact with it, such as livestock that grazed on faeces-contaminated pastures. Within the intestines of these 'intermediate hosts', the eggs hatched and a new larval stage penetrated the intestinal wall, travelled through the host's bloodstream and came to rest in any number of locations, particularly the lungs or the liver. There it integrated itself into the host's tissues and developed into a cyst, on whose sheltered interior a multitude of larval parasites thrived. Carnivores that gained access to these bodies consumed the larvae, and the cycle began again.

Cysts grew very slowly over the course of many years but could reach extreme sizes, containing several litres of fluid, 'swarming' with thousands of larvae. ${ }^{13}$ Outside this restless vitality, however, cysts seemed remarkably benign. E. granulosus parasites appeared to work away unnervingly: rooting themselves tenaciously in the host's tissues, growing perpetually, and remaining entirely invisible to the outside observer. Australian E. granulosus researcher Harold Dew had observed in 1930 how the cyst 'merges gradually and intimately into the tissue of the host', ${ }^{14}$ to the extent that 'there seems to be a perfect symbiosis between the parasite and the host tissues'. ${ }^{15}$ As a result, cysts often went unnoticed by their hosts.

${ }^{12}$ E. granulosus is the smallest tapeworm; compared with the pork tapeworm, Taenia solium, which can reach a length of 7 metres, the maximum length of E. granulosus is 6 millimetres: Craig and Faust (1964) pp. 640, 657. Of 'the many parasites which infest man', prominent parasitologist and veterinary doctor T.W.M. Cameron claimed in 1927 (p. 547), 'none is more serious than the larval stage of tapeworm of the genus Echinococcus.' For other examples of claims that E. granulosus infection is the 'most serious' tapeworm infection, see Rausch (1952), Noble and Noble (1964) and Baer (1971).

13 'swarming with scolices' from Barnett (1939) p. 593.

${ }^{14}$ Dew (1930) p. 275.

${ }^{15}$ Dew (1958) p. 448. At the time, Dew wrote that 'symbiosis' might have been taken to mean merely that two different animals live together, with no connotation of benefit or cost in the relationship. This strict definition of 'symbiosis' subsumes a range of phenomena, from severely asymmetrical relationships (e.g. parasitism) to symmetrically beneficial relationships (e.g. mutualism). However, since its first invocation in 1877, the meaning of 'symbiosis' has often been confused and regarded by many as a synonym for 'mutualism'. (On the shifting definitions of 'symbiosis', see Sapp (1994), especially pp. 3-34). Taking this into consideration, in the context of a paper already focused on a parasitic organism, the inclusion of the word 'symbiosis', particularly as it was preceded by the word 'perfect', suggests that Dew saw the relationship between Echinococcus and its host as at the very least ambiguous, and not strictly deleterious to the host, despite the fact that he, as a surgeon, had seen his share of the damage that the cysts could do to the human body. 
The abbreviated lives of sheep meant that few ever suffered symptoms of echinococcosis, although its presence was frequently revealed on the transformation of their bodies into meat. ${ }^{16}$ In humans (which were only infected via definitive hosts, such as dogs, and not other intermediate hosts, such as sheep ${ }^{17}$ ), cysts were often discovered only when in the operating theatre for a different reason, or undergoing post-mortem examinations (after death by an entirely different cause). However, later in human life when cysts grew so large that they began to impinge on the functioning of an organ, or when-as in the case of J.O.- a cyst burst, the implications for human health were severe.

The life cycle and habits of E. granulosus suggested a wily and insidious parasite which managed simultaneously to present a health threat to humans and to perform the movements of a complex animal in its own right. It was seen as an animal that had its own ecological demands and outputs, and was capable of having tangible and intangible effects on its larger animal hosts-which constituted a responsive ecosystem for the equally responsive parasite, and through which it associated into a 'host-parasite biological unit'. ${ }^{18}$ These features had already attracted the attention of a number of researchers. Following the disciplinary norms of parasitology, they had worked in the laboratory to probe the interactive relationships between E. granulosus and its human-animal hosts, and the participants' physiological and biochemical responses to that relationship. At AUB, during the 1930s, an earlier generation of parasitologists had attempted to induce immunity to infection in Lebanese populations

\footnotetext{
${ }^{16}$ For example, in 1852, T.H. Huxley was called in to London Zoo to examine the remains of a 'fine female zebra' who died of an accidentally broken neck, and whose liver had been revealed, on post-mortem examination, to be 'one mass of cysts, varying in size from a child's head downwards'. Nevertheless, the zebra itself 'had always appeared to be quite healthy, and it was in perfectly good condition.' Huxley (1898) p. 197. Veterinarians, doctors and parasitologists all marvelled at the appearance of these hosts, whom they could only ever describe as vigorous specimens: infected humans were most often 'well nourished and of an athletic physique', while non-human hosts, whether monkey or moose, were evidently 'in good health.' For the human patient, see Tenenbaum (1937); for the monkey, see Nelson and Rausch (1963); for the moose, see Rausch (1952).

${ }^{17}$ The definitive host is the one in which a parasite reaches sexual maturity. In intermediate hosts, the parasite passes through asexual larval stages.

${ }^{18}$ Baer (1971) p. 8. This was often taken to the extreme of assuming that evolutionarily older host-parasite relationships would be, as a rule, more benign — an assumption with staying power despite being debunked multiple times. Méthot (2012).
} 
of sheep and dogs. Promising results were obtained, but as the immunization was only ever partial, and soon the researchers returned or emigrated to the USA, the programme lost energy. ${ }^{19}$

Schwabe revitalized this defunct AUB research programme through his parasitological practices. Between 1958 and 1965 he and his team published more than 15 papers on E. granulosus. They began by closely examining the interface between its cysts and the bodies of its hosts. Conceiving of E. granulosus as both responder to and shaper of its host environment, they addressed longstanding questions: Was it the agent of a dangerous infection or was it a peaceful symbiont? Was the cyst fundamentally inert or vitally alive? How did the parasite's ecosystem-the interior world of the host-affect its ability to thrive? ${ }^{20}$

Answering these questions required attention to the physiological mechanisms of the parasite. Schwabe and his team probed how cysts grew and how they exchanged fluids and gases with the interior host ecosystem. ${ }^{21}$ Their tables of data reveal efforts to correlate the weight of the cyst with varying salt concentrations in its environment. These observations, and their prior conceptions of E. granulosus as an active animal, capable of responding to its environment and shaping it to suit its own needs, led them to conclude that the cyst was able to actively maintain its internal water level relative to the water in its environment, through its own 'behaviour' rather than as a result of passive diffusion across the membrane of the cyst. ${ }^{22}$

To conduct these enquiries, Schwabe needed to find ways of encouraging vigorous growth in his parasitic subject. Consequently, he sought new conditions and new host animals in the hope of finding-in the words of Webster and Cameron, writing in 1961 - a way to 'maintain hydatid infections which grew rapidly and luxuriantly in animals which

\footnotetext{
${ }^{19}$ Because the widespread infection of dogs was recognized as the primary problem in Beirut, these AUB researchers had focused on the possibility of immunizing dogs against the parasite. For example: Turner et al. (1936). After multiple AUB parasitologists relocated or returned to the USA soon after these studies, E. granulosus research in Beirut dwindled.

${ }^{20}$ His team mainly comprised parasitologists whom Schwabe had either brought to AUB or worked hard to promote, and all of these launched successful research careers working with Schwabe during this period.

${ }^{21}$ For example: Farhan et al. (1959), Schwabe (1959) and Schwabe et al. (1959).

${ }^{22}$ For the table and reference to cyst's 'behaviour', see Schwabe (1959) p. 21.
} 
could be kept conveniently in the laboratory'. ${ }^{23}$ Paradoxically, therefore, although Schwabe, like earlier researchers, worked under the auspices of disease prevention, funded and motivated through the desire of governmental agencies and corporations striving to control and prevent parasitic infection in humans and livestock, ${ }^{24}$ his actual research sought to stimulate their 'rapid' and 'luxuriant' growth in the laboratory. Parasitologists thereby became parasites' allies: their experimental protocols provided material resources for the parasites' success, while the parasites became dependent on their efforts for their survival.

This approach can also be seen in efforts to test the survival and vitality of larvae in response to different hosts, which was a common parasitological practice. E. granulosus researchers found a great deal of variation in patterns of response. For example, they found that cysts from a sheep could easily infect mice and rabbits, but rarely rats; part of their task was then seeking the factors that made such cross-infection more or less successful. ${ }^{25}$ For his part, Schwabe collected cysts from a human brain and coaxed them back to life in a 'secondary' mouse hosta form of cross-infection that had proved exceedingly difficult in the past. Cutting open the mouse's abdomen, he discovered and photographed enormous clusters of cysts. Micrographs of cyst cross-sections showed the parasitic larvae multiplying on its interior. ${ }^{26}$ These findings made visible the extent to which the parasite had altered the interior cellular landscape of the host. They laid bare the processes that usually happen beyond the sensory and analytical reach of medical scientists. Through such work-which constituted a type of human-non-human 'co-evolutionary process'-E. granulosus was transferred experimentally from one animal body to another, and gained access to new host species and a form of immortality. ${ }^{27}$ In return, Schwabe gained an enriched

\footnotetext{
${ }^{23}$ Webster and Cameron (1961) p. 877.

${ }^{24}$ For example: Schwabe (1959).

${ }^{25}$ From Australia to France, in centres of vigorous Echinococcus research, parasitologists paired studies of the minute chemical properties of the hydatid cyst wall with experiments attempting to pass those same cysts from humans to pigs, or to transfer cysts between rabbits, squirrels, mice and gerbils. Others found that cysts from sheep could infect mice and rabbits, while rats resisted infection; conversely, cysts from horses could infect mice and rats, while rabbits were resistant. All of these cases are reported in Webster and Cameron (1961) p. 878.

${ }^{26}$ Schwabe et al. (1959) pp. 31-4.

${ }^{27}$ Benson (2011) p. 5.
} 
knowledge of the parasites' behaviour and a new level of control over them in the laboratory.

As E. granulosus allied itself with Schwabe, he responded in kind, relying upon the parasite in his efforts to advance his career. As the sole faculty member of AUB with veterinary training, Schwabe was under especially intense pressure to demonstrate his particular value to his medically trained (and occasionally dubious) colleagues. ${ }^{28}$ Working on E. granulosus enabled him to elaborate his professional network, ${ }^{29}$ building bridges across departments at AUB, actively collaborating, for example, with colleagues in the chemistry department, who had the instruments and techniques he needed to gauge the osmotic balance maintained by his tapeworm subject within the host's body. ${ }^{30}$ As with the other animals whose histories are documented in this volume, $E$. granulosus promoted working across disciplinary boundaries as much as species boundaries. It also enabled Schwabe to revitalize AUB as a centre for E. granulosus research. In his unpublished autobiography, he writes of the visits of many international researchers, in an expanding network that would continue to be invaluable to him in the coming decades. ${ }^{31}$ Indeed, his growing experience with the parasite seems to have been the primary factor that drew many of these researchers and which established him as one of the world's experts on it. ${ }^{32}$

\footnotetext{
${ }^{28}$ In his autobiography, he describes his position as the only veterinarian, writing that his choice of research subject was a consciously strategic decision. By his recollection, he was also the youngest department chair in the history of AUB. He recounts some early challenges to his expertise, including an instance of one of his colleagues bringing him what he (the MD) assumed was a fungal infection but which Schwabe revealed to be a parasite. Schwabe (n.d.) p. 217.

${ }^{29}$ For example, in the Webster and Cameron paper cited above (1961), both Calvin Schwabe and prominent Swiss parasitologist Jean Baer (mentioned above) are thanked for the provision of infective parasitic material and infected hosts. Schwabe sent E. gramulosus from Lebanon and Baer sent an infected vole from Switzerland. Additionally, researchers from Alaska, Toronto, Chile and other locations contributed material for the research (all thanked on p. 880), thus demonstrating the complex web of professional connection and recognition that was enabled by this parasite.

${ }^{30}$ Farhan et al. (1959).

${ }^{31}$ Schwabe (n.d.) pp. 93, 95.

${ }^{32}$ According to his own recollections in his autobiography, that is, but also-as the following sections will demonstrate- the degree to which the WHO came to rely on him suggests the same.
} 


\subsection{Echinococcus Leaves the Laboratory: Schwabe's Parasitology at the Population Level}

While it was the parasite's dynamic interaction with individual host bodies that first captured Schwabe's attention, leading him to conduct laboratory-based investigations into the bodies of experimental animals, its movement beyond this narrow sphere subsequently pushed him to examine the host-parasite interaction writ large - that is, on the human population of Beirut. For the first time in his career, he began to focus on the buman animal. Via this new species of host, his parasitic subject led him to develop newly epidemiological pathways of enquiry.

These enquiries began in the hospital operating theatre, where signs of E. gramulosus infection in humans first typically surfaced in the hydatid cysts made visible through surgical disruptions to bodily integrity. Thanks to a widely ranging and heavily infected dog population, human infection was rampant in Beirut, and for this new component of his research, Schwabe accessed a trove of data. He began with the records of 54 Lebanese hospitals, analysing the detailed records of 918 surgical cases that had addressed or uncovered E. granulosus infections between 1949 and 1959. The correlations he found were striking - in pursuing his pet parasite, Schwabe had stumbled onto a powerful set of insights about the importance of human cultural traditions in parasitic infection. Christian patients, he found, numbered twice as many as Muslim. ${ }^{33}$ The study, published in 1961, claimed that 'religion was a real epidemiological factor', ${ }^{34}$ positing Muslim cultural prohibitions against close contact with dogs as a possible explanation. Later efforts to gather further data suggested that Christian families were more likely to keep dogs as family pets and to encourage children to develop affectionate bonds with them. ${ }^{35}$

\footnotetext{
${ }^{33}$ Schwabe and Daoud (1961) p. 377. They also found that shoemakers experienced the disease disproportionately, surmising that placing shoe tacks and thread in their mouths might make them more susceptible. Later it was recognized that dog faeces was used in the process of tanning leather, which explained infection in shoemakers and other people working with leather in Lebanon.

${ }^{34}$ Ibid. p. 379.

${ }^{35}$ Abou-Daoud and Schwabe (1964).
} 
On the level of the population, then, through a complex of culturebound interactions between humans and dogs, Schwabe had discovered another way in which E. granulosus responded to and shaped its environment. In this case, statistics captured how the parasite infiltrated the cultural ecosystem of Lebanese society. Dogs were ascribed a variety of roles, from companions to stray mongrels, some welcomed into the human sphere and some excluded from it. In either case, canine relationships with humans became a key ecological factor that enabled or obstructed the parasite's passage to humans. In invoking the importance of these domestic social relationships alongside surgical data, Schwabe used ephemeral connections between humans and dogs to follow the parasitic animal as it moved from one host ecosystem to another. The parasitological research tradition had been driven in just this manner, by animals such as E. granulosus, which, in responding to their environments, often created new symbiotic relationships that were based on the biological qualities of the host animal-Schwabe expanded on this tradition in his explicit inclusion of their social and cultural behaviours as well.

With his success at AUB, Schwabe's sphere of influence grew and he increasingly took to the global health stage. In Beirut he had pursued $E$. granulosus into the human realm, finding that movement between nonhuman and human research gave him a fuller sense of the parasite's biology. This work only expanded when the WHO first asked him to travel on their behalf in 1960, contracting him to visit Cyprus and investigate the island's endemic E. granulosus. This trip was quickly followed by a series of trips to multiple far-flung centres of E. granulosus infection, from New Zealand to Argentina, which would mark the initiation of the WHO's global effort to control the disease. ${ }^{36}$ Most critical for his own career at this time, however, was Schwabe's trip to Kenya in January 1961, on a Fulbright Scholarship that would relocate his family to a home outside Nairobi for the entire year. ${ }^{37}$

While Schwabe's explicit goal during his stay in Kenya was to finish writing the manuscript that would become his first edition of $V M H H$, he pursued the E. granulosus parasite into this new setting as well. In 1958, a brief 'Note on Human Hydatid Disease in Kenya', published

\footnotetext{
${ }^{36}$ On his travels see Schwabe (n.d.) p. 260 , and p. 8 for a statement that he initiated the programme.

${ }^{37}$ Schwabe (n.d.) pp. $439-41$.
} 
in The East African Medical Journal, had captured his attention. It suggested an unusually high level of E. gramulosus infection among the pastoralist tribes of Kenya - the Turkana and the Maasai. In this 'intriguing' note, which Schwabe would still remember decades later, ${ }^{38}$ J.R. Wray, a British medical officer in the rural northwest of the country, claimed to have operated on twenty-five human hydatid cysts in three years. Wray also made a series of surprising assertions about the path taken by the E. granulosus parasite in this environment, so far from the Lebanese city where Schwabe had first encountered it. Wray suggested that, in Kenya, E. gramulosus might find its way into the guts of wild carnivores, such as hyenas and jackals, and then infect tribespeople through 'their habit of smearing themselves with earth'. This inference, of the possible involvement of wild carnivores, was based partly on a lack of data on infection in dogs; a 'definitive' host, the role fulfilled by canids, was required for $E$. granulosus to complete its life cycle. However, Wray had an even more intriguing hypothesis about the parasite's movements in store: Because, he wrote, Maasai tribespeople did not inter their dead, but left their bodies where they could be consumed by wild carnivores, E. granulosus may even have found a way to cycle directly between humans and carnivores. ${ }^{39}$

The implications of this case for Schwabe-a parasitologist trained in veterinary medicine, just making his first forays into human medicinewould have been extraordinary. The tradition in the parasitological literature of the preceding decades had been to consider the human host a 'dead-end' for E. gramulosus, an 'accidental host', relative to the sheep, which served as the 'normal', 'natural' or 'usual intermediate host' for the parasite. ${ }^{40}$ In fact, graphic depictions of the E. granulosus life cycle most often feature a dog and a sheep in the centre; a human host may be excluded entirely from the image ${ }^{41}$ or decentred, visually communicating its 'dead-end' status. ${ }^{42}$ After all, the cysts embedded in the sheep's

\footnotetext{
${ }^{38} \mathrm{He}$ recalls the 'intriguing' note in Schwabe (n.d.) p. 444.

${ }^{39}$ Wray (1958).

${ }^{40}$ For example: Bogitsh et al. (2005) p. 288.

${ }^{41}$ For example: ibid. p. 290. The exclusion of a human from the diagram is especially interesting, given that this is a textbook on human parasitology.

${ }^{42}$ For example: 'Parasites-Echinococcosis' (2012).
} 
flesh or organs are far more likely to be eaten by a dog, which then perpetuated the infection. By contrast, owing to culturally contingent burial practices, the human host, while physiologically identical to the sheep from the perspective of E. granulosus, is highly unlikely to be consumed by a dog or any other carnivore after death. Thus the infection typically passed from dog to human ends there, and the cysts 'swarming' with larvae die soon after their human host passes away. But the Kenyan case raised a new question: What if an infected human body were actually made available for consumption by canines, upending parasitological expectations with an unusual human cultural practice? In that case, suddenly the assumption that humans were 'accidental' hosts would reveal itself to be a strangely anthropocentric way of dividing human bodies from those of other animals.

Schwabe's interest in how E. granulosus might travel through this network of biological and social connections spurred a new investigation into the shared parasites of pastoralist human and wild carnivore populations in Kenya. On arriving in Kenya in 1961, Schwabe quickly teamed up with British parasitologist George Nelson, who worked at the Medical Research Laboratory in Nairobi. Nelson was eager to have Schwabe join him on safari in order to examine the gut contents of hyenas in person. Having killed a zebra as bait, they sought hyenas for hours until eventually Schwabe was rewarded by the clear evidence of E. granulosus infection in the guts of three hyenas, which they caught and dissected. ${ }^{43}$

Schwabe also had the opportunity to directly observe the human pastoralist infection that so intrigued him. In March 1961 the medical officer holding Wray's old post, some 200 miles north of Nairobi, contacted Schwabe to invite him to witness - and, ultimately, assist-in the surgical removal of a very large abdominal hydatid cyst. Schwabe combined this powerful surgical experience with an examination of the records of this 'one little bush hospital', after which he estimated that the infection rate of Turkana tribespeople was 'probably higher ... than any other population in the world!' ${ }^{44}$ Writing in $V M H H$ soon after this

\footnotetext{
${ }^{43}$ Schwabe (n.d.) pp. $445-6$

${ }^{44}$ Ibid. p. 448. It is important to note that many of the details found in Schwabe's autobiography, cited here, are corroborated by family correspondence, which he quotes and cites extensively in the text, particularly between his wife, Tippy, and her parents.
} 
experience, he calculated the rate of E. granulosus infection in this population to be ' 40 per 100,000 per year (or approximately three times the highest known national rate, which is that of Cyprus)' ${ }^{45}$

His description of E. granulosus among the Turkana in VMHH makes clear, however, that the case represented more than just a startling epidemiological statistic. Bracketed in the text by his account of the parasite's path through Beirut and the mysteriously high rate of infection in human forestry workers in New Zealand, the story of Turkana infection exemplifies Schwabe's mounting interest in the way that intangible social relationships provided opportunities for E. granulosus to find new niches and transgress the boundary between non-humans and humans in surprising ways. ${ }^{46}$

The story of E. granulosus in Kenyan pastoralists was ultimately revealed to hinge more on the 'intimate contact from a very early age' between Turkana children and the numerous dogs kept by their families (as well as plentiful and E. granulosus-laden livestock). ${ }^{47}$ Though it did not revolutionize the perception of the human as an 'accidental' host of the parasite, Schwabe's experience in Kenya came at the same time that he was writing the first edition of $V M H H$, when he was just beginning to articulate what would become a lifelong challenge to the validity of the boundary between humans and other animals. First he had followed the parasite through the laboratory, cultivating its health and proliferation as he considered how it moved between different non-human hosts and examining the minuscule biochemical exchanges that made these intimate interactions possible. However, by the time he was completing VMHH in 1961, the parasite had drawn him out of the laboratory and across the species boundary between non-humans and humans, where cultural exchanges became just as critical to intimate host-parasite relationships as the biochemical interactions observed in the laboratory.

\footnotetext{
${ }^{45}$ Schwabe (1964) p. 211.

${ }^{46}$ Ibid.

${ }^{47}$ Nelson and Rausch (1963) p. 145.
} 


\subsection{Following Echinococcus Across the Globe: Schwabe's Persistent Parasitology}

The human dimension of Schwabe's research, and particularly his search for the path of the parasite through the cultural practices and social relationships of human hosts, only grew in the next few years. At the same time, the global ubiquity of E. granulosus was increasingly acknowledged, ${ }^{48}$ which also provided Schwabe, reciprocally, with pathways to new career opportunities. Through the parasite, then, the scope of his work grew, as he took on increasing responsibility and reward with the WHO ${ }^{49}$ It remained at the centre of his work throughout this period, a driving force that is felt only more distinctly after considering the sheer variety of methodological approaches that he took to pursue it between animal bodies, across landscapes and between continents.

As well as a vehicle for Schwabe's professional ambitions, E. granulosus also became a medium for the building of bridges across disciplines and between nations. Using his expertise on E. granulosus as currency, he gained increasing access to the networking possibilities of the WHO, forging a lasting friendship with Martin Kaplan, head of its Veterinary Public Health (VPH) unit, as he continued to work for the WHO as a contractor. This friendship would prove pivotal for Schwabe when the WHO finally offered him a permanent job in 1964, when he and his family moved to Geneva for two years. ${ }^{50}$ Kaplan's work for the WHO is described in detail in Chapter 4, where his efforts to promote human health and nutrition through the prevention of livestock disease are highlighted. Joining the VPH had at first been mentioned to Schwabe.

\footnotetext{
${ }^{48}$ For example, a Web of Science search for the term 'Echinococcus' between 1940 and 1970 shows a scant 3-6 publications per year through the early 1950s. In the last half of the 1950 s there were $7-9$ publications per year. Through the 1960 s, these numbers grew, reaching 20 in 1966, 20 in 1967, 31 in 1968 and 25 in 1969.

${ }^{49}$ While his research funding had previously been dominated by Pfizer and the US National Institute of Allergy and Infectious Diseases (part of the NIH), his publication record shows that in 1961 he began to receive grants from the WHO. For this shift, see Kilejian et al. (1961).

${ }^{50} \mathrm{On}$ the developing friendship and ongoing correspondence between Kaplan and Schwabe, see Schwabe (n.d.) pp. 259-60, 310. Later, after his move to the University of California-Davis, Schwabe attempted to recruit Kaplan to join him. For example: Schwabe (1967).
} 
In the event, however, he became 'second in command' of the Parasitology Disease (PD) unit, which he considered to be the " "nerve centre" of medical parasitology worldwide'. Like VPH, PD took human health to be a goal of primary importance. However, Schwabe's persistently broad interest in the lives of parasites in general, and the fact that E. granulosus infection in animals did not immediately threaten human health, made PD a better fit for his work. It offered him the opportunity to keep the parasite at the very centre of enquiry. He helped to track infection rates and run prevention programmes for a number of parasites, from soil-transmitted helminths such as hookworm to fungi that caused animal disease. He combined this pursuit of human health with investigations into a variety of aspects of parasitology, such as taxonomy and evolutionary history, which some medical researchers might have regarded as somewhat esoteric and ancillary to medical concerns. For Schwabe, then, working for PD enabled him, in large part, to follow parasites where they led him. ${ }^{51}$

This was true also in a geographical sense. In 1965 alone, Schwabe visited eight countries during the months of July and August. ${ }^{52}$ And while his time at the $\mathrm{WHO}$ was a whirlwind of consulting on a range of parasitic infections, coordinating international meetings, and producing technical reports and bulletins, he also continued to focus on E. granulosus in these travels and draw conclusions about the array of human social and cultural niches into which the parasite could insert itself. Through Schwabe's efforts to correlate findings in a vast array of different environments and human cultural contexts, E. gramulosus built increasingly elaborate and transnational connections-for example, bringing Nelson in Kenya into collaboration with a prominent American E. granulosus researcher, Robert Rausch, to compare the parasite in the wild hyenas of Kenya with the sylvatic transmission cycles of wolves and moose in Alaska. Enabling such connections inspired Schwabe, and he later recalled that this was 'what I first visualized trying to do for WHO'. ${ }^{3}$

Nevertheless, despite his enthusiasm for some aspects of the job, Schwabe was not long for the WHO, and in his memoir he suggests that

\footnotetext{
${ }^{51}$ Schwabe (n.d.) pp. 287, 310.

52 'Duty Travel' (n.d.).

${ }^{53}$ Schwabe (n.d.) pp. 319, 446.
} 
it was the bureaucracy that ultimately wore him down. ${ }^{54}$ In 1966 he was offered a new position at the University of California, Davis, where he could help build connections between the School of Veterinary Medicine and the School of Medicine. After a decade living abroad, he and his family returned to the USA.

For Schwabe, moving to California had one significant scientific drawback: the apparent absence of his 'paradigmatic parasitism'. The search for 'autochthonous' E. granulosus infections-those thought to have originated in the USA - had turned up only 40 cases by the end of the 1950s, which served as an extreme contrast to Schwabe's previous setting of Beirut. ${ }^{55}$ A true symbiont, however, E. granulosus had shaped Schwabe's career and his perceptions of successful science so profoundly that he could not entertain the possibility of giving it up, even in a new context that seemed far less promising for the parasite's prospects. Moreover, as he reflected on the importance of the parasite after retirement, Schwabe quoted William Osler, writing that one should ' $[\mathrm{k}]$ now one disease completely and you will know all of medicine'. For Schwabe, that 'one disease' was echinococcosis and 'that one parasitism' would serve him, in his own words, 'as a sort of paradigm for a modern comprehensive parasitology'. ${ }^{56}$ His commitment to this philosophy is vividly expressed here; instead of considering the study of a different parasite, Schwabe began to consider how he might bring E. granulosus with him, reflecting on ways to ramp up his previous efforts to develop better laboratory hosts for the parasite. ${ }^{57}$

Fortunately, however, E. granulosus had reached California long before Schwabe did, proving again its insidious potential for utilizing

\footnotetext{
${ }^{54}$ Ibid. p. 324.

${ }^{55}$ For example: Cobgill (1957), Brooks et al. (1959) and Sterman and Brown (1959).

${ }^{56}$ Schwabe (n.d.) p. 333.

${ }^{57}$ This was not a straightforward task, and it was always a challenge to establish secondary infections in rodents and other experimental animals by transferring cysts as he had done at AUB. Schwabe et al. $(1964,1970)$. He was able to call on his existing network of Echinococcus researchers for their help. (See Rausch (1967) on shipping him a vole infected with Echinococcus). The patterns of international correspondence, visits and network-building via the study of this parasite, which he had established at AUB, continued at University of California, Davis without interruption.
} 
myriad human movements and connections to colonize new environments. One morning, soon after his arrival in Davis, one of Schwabe's students made an unexpected discovery in a local abattoir. The student was a US Department of Agriculture veterinarian, studying with Schwabe and working in his lab, and he had been sent to collect sheep viscera in order to identify their parasitic fauna. However, he had not expected to uncover his mentor's pet parasite in the process. He returned to Schwabe's laboratory eagerly, impatient to show him the sheep livers he had collected-full, as he believed, of E. granulosus cysts. Subsequent examination of local sheep carcasses confirmed that the parasite was present and thriving in California. For example, in a January 1968 examination of a group of 227 sheep sent to a local abattoir (from the farm owned by the family of J.O., in fact), 225 were found to be carrying living E. granulosus cysts. ${ }^{58}$ Schwabe eagerly reactivated his research programme and undertook to track the worm through its local populations of hosts.

His efforts would overturn assumptions about E. granulosus in the USA, showing the parasite to be well established in the state of California. In 1969, Schwabe wrote to a colleague in Tasmania, who was heading up the E. granulosus control effort there, telling him:

You will have to revise your assumption about the absence of hydatid infection in sheep and dogs in North American sheep [sic] ... At present we have demonstrated transmission in eight counties of the Central Valley of California, spanning almost the entire length of the state. This included infected coyotes in two counties and several human cases so far. In one recent fatal case, all 13 of the man's dogs were infected!

His Tasmanian colleague replied: 'The paper of course fascinated me, especially after spending a year in California wondering how you had escaped infection. ${ }^{59}$ From the Tasmanian researcher's perspective, the many sheep ranches of the Central Valley of California had presented an obvious conundrum: The conditions suggested an ideal environment for E. granulosus, yet the region had ostensibly 'escaped infection'. The

\footnotetext{
${ }^{58}$ Araujo et al. (1975) pp. 291, 298.

${ }^{59}$ Schwabe (1969).
} 
discovery made by Schwabe's student at the abattoir had revealed, however, that the Central Valley had not escaped infection after all. Instead, the parasite had remained concealed, and part of Schwabe's task would be to understand how the parasite had flourished and why it had gone mostly undetected. Previously, Schwabe had laboured to elucidate the network of connections forged by E. granulosus in the human and canine populations of Beirut; now he would do the same in the Central Valley of California. ${ }^{60}$

As before, hospital surgical records provided an important starting point for his investigation. Surveying and tabulating data about cysts taken from human patients and from sheep in local abattoirs allowed Schwabe to begin to reconstruct the history of E. granulosus in California, following the trail of the parasite back to the initial sites of infection. Both sets of traces led to the Basque sheep-farming community from which J.O. and his father, Salvador, hailed. Once Schwabe began to focus on Basque sheep farms, he took multiple tacks: deworming dogs; examining sheep; and interviewing family members and shepherds. Most of the potential human and non-human hosts that he and his team encountered, however, were asymptomatic and healthy, effectively obscuring the real level of infection and requiring immunological testing in order to infer infection. Soon it was clear, from all of these forms of data, both direct and indirect, that humans, sheep and dogs on these farms were all subject to infection by E. granulosus.

Following the parasite through the precise points of contact between the hosts, however, required that Schwabe employ the methods he had developed in following the parasite in Beirut, interrogating the social interactions and mores that created the interspecies pathways exploited by E. granulosus. In order to understand the relationships between Basque immigrants, sheep, dogs and E. gramulosus, Schwabe needed a far more intimate look at the workings of these farming operations. In 1972 he sent anthropology graduate student Frank Araujo to live and work on a Central Valley Basque sheep ranch, where-like

\footnotetext{
${ }^{60} \mathrm{He}$ was also able to place this into the context of fairly extensive experience in far-flung locations and diverse cultures (e.g. the Turkana people of Kenya) and control programmes in many different countries (e.g. New Zealand and Iceland). For example, Burridge and Schwabe (1977) consider infection among New Zealand's indigenous Maori population.
} 
the late nineteenth-century British experts whose investigations were described in Chapter 3-he sought to learn about disease directly from sheep farmers. Thanks to his own Basque ethnic heritage, Araujo had a functional knowledge of the language, which allowed him to press family and workers for, in his own words, 'ethno-veterinarian lore' and 'an outline of the decision-making procedures' used on a typical Basque sheep farm. ${ }^{61}$

Though he was trained in anthropology, Araujo examined this community through an ecological lens, seeking the interrelationships that made the system work. In writing up this research, his language demonstrated that each component of the 'ancient transhumant type of mansheep-dog ecosystem' was invested with agency, including the parasite itself; in addition to the 'close interrelationships between these three [host] species,' he wrote, 'a fourth species, Echinococcus granulosus, traditionally derives comfort and prospers too, once it has been introduced'. ${ }^{62}$ An ecological perspective is apparent even in Araujo's anthropological observations. In his initial research proposal, he wrote of the exchanges that made the Californian sheep industry function, moving goods like wool and meat from the fairly insulated Basque community to the larger body of consumers, in a manner 'characteristic of a symbiotic relationship'. ${ }^{63}$ This mode of description was echoed in his 1975 publication, co-authored with Schwabe and others, where he described the Basque sheepherding economy as the 'successful exploitation' of a 'marginal ecological niche, with a transhumant and complementary utilization [of] ... seasonally useless land', which has, as a result, allowed the Californian population of Basques the 'preservation of their ethnicity'. ${ }^{64}$

The system worked by dividing a rancher's ewes into groups of $600-800$, and taking them by truck to roam in small bands over leased land in the Sierra Nevada or the Mojave Desert. While one 'camp tender or kanpero' would live in a central location in a trailer, providing the sheepherders or artzainak with essential supplies, the latter would roam on foot with their bands of sheep, living in a tent along the way. All of these-sheep, humans, dogs and their invisible internal companionswould be taken back to their home ranches in the San Joaquin valley at

\footnotetext{
${ }^{61}$ Araujo (23 June 1972).

${ }^{62}$ Araujo et al. (1975) pp. 300-1.

${ }^{63}$ Araujo (n.d.) p. 3.

${ }^{64}$ Araujo et al. (1975) p. 295.
} 
critical times. ${ }^{65}$ Araujo and Schwabe recorded these transhumant migrations using arrow-laden maps of the state of California, from which they concluded: "This system of husbandry results in the possibility for large areas of crop and recreational lands in California to be seeded with $E$. granulosus eggs from the feces [sic] of infected sheep dogs. ${ }^{66}$

In addition to mapping out the scale at which E. granulosus traversed the state of California, Araujo mapped out the more intimate and detailed passages of the parasite, through a linguistic, figurative understanding of the relationships between the four core species of animals. Most significantly, he observed and participated in farming practices, seeing that sheep were being fed the carcasses of deceased, and often diseased, sheep. Many ranchers denied that this practice continued on their farms. However, evidence pointed to its perpetuation: most transparently, the presence of tapeworms (E. granulosus and others) in sheepdogs with little opportunity to be infected elsewhere, which indicated that they had been consuming raw meat. In fact, as Araujo recorded, the practice was common enough: he himself was employed to do it, though he attempted to mitigate the effects by removing suspicious-looking cystic lumps from the eviscerated sheep before letting the dogs loose to feed on them. From the months that he spent living among and communing with the ranch hands and shepherds, Araujo learned that it was generally believed that a good sheepdog needed to eat sheep viscera. He also learned that few of the shepherds connected their own hydatid cysts to the 'stones or pebbles' that they saw when they gutted the dead sheep and left them to the dogs. ${ }^{67}$ Indeed, he observed, most of the ranchers and sheepherders he had come to know seemed to think nothing of the frequent appearance of abscesses and pathological tissue in the flesh and organs of their dead sheep. ${ }^{6}$ In other words, he concluded, 'folk knowledge' had not led the Basque community to make the inferences that they would have needed to arrest the constant cycling of E. granulosus between their sheep and dogs.

\footnotetext{
${ }^{65}$ Ibid. pp. 295-6.

${ }^{66}$ Ibid. p. 296.

${ }^{67}$ Araujo (5 July 1972). Writing about his anthropological-epidemiological fieldwork, Araujo said that many of the sheepherders 'don't seem to know (or care!) what causes them', and one proclaimed it to be 'bullshit.' Araujo (14 November 1972).
}

${ }^{68}$ Araujo (14 November 1972). 
Complementing Basque beliefs about sheepdogs' dietary requirements and their lack of knowledge about cysts, the transhumant patterns described above left shepherds, dogs and sheep in joint isolation for long periods of time, on a series of lands located at a distance from the home ranch. In these circumstances, feeding dogs on dead sheep provided a convenient source of sustenance. After all, the profit margins in the industry were small, and wasting the meat of a dead sheep seemed uneconomical. More profoundly, however, Araujo and Schwabe claimed, in this isolating system of ranching, '[r]elationships between shepherds, dogs and sheep are highly mutualistic', with the means of subsistence literally enabled or provided to each other by each member of the tripartite relationship. ${ }^{69}$

Araujo's study also revealed the presence of additional links in this ecosystem. Taking a day to follow a sheep owner and his favourite dog, he carefully recorded the manifold contacts the dog had with people of all ages and stations at the ranch, particularly the children. And in observing the dumping of excess dead sheep, he suggested the possibility that wild canids-coyotes and feral dogs-might also provide new host environments for E. granulosus. ${ }^{70}$ The entanglement of wild animals in the parasite's movement through domestic and agricultural systems had been verified in multiple contexts, as we have already seen in this chapter. As with the hyenas in Kenya, Schwabe and his collaborators discovered that the parasite had found another cohort of hosts in coyotes and had, in fact, also begun to exploit deer as an intermediate host, in place of sheep..$^{71}$

As American E. gramulosus continued to draw attention to itself, it soon became apparent that it had found its way to other human communities that practised modes of animal husbandry similar to those of the Basques. Like Californian coyotes and Alaskan moose, these disparate groups of people had been caught up in a series of new, loosely interconnected ecosystems that E. granulosus, through its own mode of

\footnotetext{
${ }^{69}$ Araujo et al. (1975) p. 297.

${ }^{70}$ Ibid.

${ }^{71}$ Liu et al. (1970). The story of the parasite's path from the domestic and agricultural settings generated by humans into wild populations of animals is still developing today, particularly as the 'wild' increasingly merges into the borderland around the intensively urban. For example: Catalano et al. (2012). As Chapter 6 describes, the 'wild' is one category of animal that $\mathrm{OH}$ advocates attempt to include beneath their umbrella. Animals are primarily regarded in that sphere as disease vectors.
} 
transmission, had created. As Schwabe and his students would report in 1977, the practices of transhumant sheepherding effectively united a motley crew of American subcultures, from the Basque immigrants of California, to Mormon sheepherding communities in Utah, to indigenous Navajo and Zuni in Arizona and New Mexico. ${ }^{72}$ Expanding this view to a global scale, farmwives in Iceland, Turkana tribespeople in Kenya and Cypriot islanders were also members of this ecosystem, connected as well to the deer, coyotes, moose, wolves and various other animals in which E. Granulosus made its home.

\subsection{Conclusion}

During the first two decades of his career, Schwabe tracked E. granulosus across multiple boundaries. Where the parasite went-from host to host, environment to environment, continent to continent and discipline to discipline-so too did Schwabe, creating professional connections that brought the tapeworm's movements and exchanges into relief. When Schwabe made the leap from studying parasites in the context of nonhuman bodies and the laboratory to studying parasites in human bodies and human cultural niches, it was not so much a leap, in fact, but a transition guided by the parasitic animal itself, and an extension of its biological autonomy. The network of scientists and medical practitioners that collaborated with Schwabe, engaging in the global effort to investigate human and animal health, can also be seen as an extension of the interactive biological networks forged by the parasite. Schwabe's graduate students and collaborators would become vital additions to those organizations that strove to track and prevent the spread of disease, from the Centres for Disease Control to the Pan American Health Organization. ${ }^{73}$

\footnotetext{
${ }^{72}$ Pappanaioanou et al. (1977) pp. 732, 738.

${ }^{73}$ They included: Peter Schantz, who was Schwabe's first PhD student at the University of California, Davis, and the recipient of the first ever $\mathrm{PhD}$ in veterinary epidemiology. Schwabe (n.d.) p. 337, Nolen (2013). See Schantz and Schwabe (1969) for an example of their collaboration around Echinococcus. Schantz went on to work on Echinococcus first at the Pan American Zoonoses Center in Buenos Aires, Argentina, and from 1974 at the Centers for Disease Control (CDC) in Atlanta, Georgia, where he was part of epidemiological research on many parasites that passed between humans and non-humans. Schantz and Colli (1973), Pappaioanou (multiple dates). For his continuing involvement in, and influence on matters concerning Echinococcus, see, for example Jones et al. (1980),
} 
Thus, just as the parasite connected far-flung populations of diverse animals and humans, it was also a primary vehicle for the development of careers, and a dispersed, multidisciplinary network of scientists, doctors and veterinarians.

In part, the extended association that Schwabe formed with E. granulosus should be seen in terms of the history of the field of parasitology, whose grounding in late nineteenth-century tropical colonial medicine and agriculture gave it a richly contextualized perspective on infectious disease from the beginning. ${ }^{74}$ Historians have noted that this field drew from natural history, zoology and medicine, taking ecological environments and evolutionary history seriously, and questioning why particular parasites thrived in some places and not others. ${ }^{75}$ This disciplinary background provided Schwabe with an enriched biological conception of interactions between parasites and hosts, which he expressed in writing with Araujo in 1975. Framing E. granulosus as the fourth member of the '[hu]man-sheep-dog ecosystem', 76 he placed it on an equal ecological standing with the other animals in the cycle of transmission, and asked how its physiological and ecological needs were met by the body of the host. This was very different from medical and veterinary approaches which tended to identify parasites with disease, and to regard them as threats to humans and animals rather than as interacting organisms in their own right. Schwabe regarded his subject primarily as an animal, and only secondarily in terms of the disease it might cause. This chapter

Moro and Schantz (2009). Likewise, Schwabe's graduate student Marguerite Pappaioanou, who also collaborated on the California programme, went on, at his recommendation and with his consultation, to work on Echinococcus on the island of Cyprus. Pappanaioanou et al. (1977), Pappaionanou (April-June 1977). Pappaioanou went on to a long career at the CDC as well, and became an outspoken advocate of $\mathrm{OM}$ and $\mathrm{OH}$. For example: Pappanaioanou (2004). These are only two examples out of a plethora of students who still influence the global health community today.

${ }^{74}$ See Chapter 3.

${ }^{75}$ On the origins of parasitology, see Farley (1972, 1992), Worboys (1983), Li (2004). Parasitology became an important basis for the development of disease ecology in the early twentieth century. For example, see Anderson (2004). It also developed a range of complex perspectives on the evolution of pathogens, and the relationship between the evolution of parasites and the evolution of hosts. Méthot (2012), Mason Dentinger (2016).

${ }^{76}$ Araujo et al. (1975) pp. 300-1. 
therefore extends the insights gained in Chapters 2 and 3, further exploring how the concurrent study of human and non-human health enables, and is enabled by, multidisciplinary scientific approaches.

Following the parasite changed the way that Schwabe saw the relationship between humans and non-humans, and between human and veterinary medicine. As he worked to complete $V M H H$ in 1961, he was simultaneously exploring the dynamic movement of E. granulosus among the hyenas and the humans of Kenya. Here, in the early years of his career, before his shift of focus to epidemiology and advocacy for OM, he developed a critique of the very concept of 'zoonosis', which he described as 'a pre-Copernican notion' that relied on and enforced a "“[hu]man-other animal" dichotomy' that could have no 'real meaning to the student of the natural history of infections'. ${ }^{77}$ In other words, thanks to the influence of E. granulosus, he was already actively undermining the basic definition of 'zoonoses', given by the WHO as 'diseases and infections which are naturally transmitted between man and animals' ${ }^{78}$ Schwabe challenged the distinction at the core of this definition, insisting that the line between humans and non-humans was not fundamentally biological but, in large part, a product of human cultural variations. ${ }^{79} \mathrm{He}$ would also ultimately extend this insight into a disciplinary critique of medicine, arguing that human and veterinary medicine were separated only by human traditions and preconceptions and not by essential differences between their subjects. In other words, one of the key innovations in Schwabe's thinking, reiterated throughout the latter half of his life, in multiple writings - that of undermining the very validity of species boundaries in biology and medicine $e^{80}$ - finds its roots at the

\footnotetext{
${ }^{77}$ Schwabe (1964) p. 197.

${ }^{78}$ This definition is taken from Joint WHO/FAO (1959).

${ }^{79} \mathrm{He}$ would later infuse this sensibility into the next report of the WHO/FAO Expert Committee on Zoonoses, from 1967, when he served on the committee. Though the report suggests that the 1959 definition should be preserved, this recommendation is preceded by a 'Schwabean' disclaimer, stating that while 'the term zoonoses is etymologically inexact and of little biological merit it is generally agreed that it is useful because it creates common ground for the medical veterinary professionals' to work together on disease understanding and prevention. Joint WHO/FAO (1967).

${ }^{80}$ Which then became a central tenet of $\mathrm{OM}$ and $\mathrm{OH}$. See Chapter 6 for more information.
} 
beginning, at a time when he was still deeply engrossed in his pursuit of his paradigmatic parasite.

Just as Schwabe tracked E. granulosus throughout his career, so too have $\mathrm{I}$ in this account. By considering the movements of the parasite and how they have ramified through the careers of Schwabe and his collaborators, I have crisscrossed the historiographical boundaries that typically stand between the history of biology and the history of medicine, and between the history of human medicine and veterinary medicine. Parasitologists have, in their pursuit of parasites, brought natural history, zoology and medicine all to bear on their human and non-human subjects. Likewise, this account has moved between all of these domains, suggesting that while an understanding of disciplinary norms and training is an essential element in our analysis of the history of science and medicine, these must not restrict the ultimate scope of our enquiry. As our subjects, of all species, repeatedly prove their ability to move beyond the many bounds that we have constructed and imagined, so too must historians.

\section{BIBLIOGRAPHY}

Abou-Daoud, Kamal and Calvin W. Schwabe. "Epidemiology of Echinococcus in the Middle East: III. A Study of Hydatid Disease Patients in the City of Beirut." American Journal of Tropical Medicine and Hygiene 13 (1964): 681-5.

Anderson, Warwick. "Natural Histories of Infectious Disease: Ecological Vision in Twentieth-Century Biomedical Science." Osiris 19 (2004): 39-61.

Araujo, Frank. "Basque Ecology in the Western United States." n.d. Calvin W. Schwabe Papers, National Library of Medicine, 21:12.

Araujo, Frank. "Correspondence with Calvin Schwabe." 23 June 1972, 5 July 1972, 14 November 1972. Calvin W. Schwabe Papers, National Library of Medicine, 21:12.

Araujo, F.P., C.W. Schwabe, J.C. Sawyer and W.G. Davis. "Hydatid Disease Transmission in California: A Study of the Basque Connection." American Journal of Epidemiology 102 (1975): 291-302.

Baer, Jean G. Animal Parasites. London: World University Library, 1971.

Barnett, Louis. "Hydatid Disease: Errors in Teaching and Practice." British Medical Journal 2 (1939): 593-9.

Beisel, Ulli, Anne H. Kelly and Noémi Tousignant. "Knowing Insects: Hosts, Vectors and Companions of Science." Science as Culture 22 (2013): 1-15.

Benson, Etienne, "Animal Writes: Historiography, Disciplinarity, and the Animal Trace." In Making Animal Meaning, edited by L. Kalof and G.M. Montgomery, 3-16. East Lansing, MI: Michigan State University Press, 2011. Bogitsh, Burton, Thomas Oeltmann and Clint Carter (eds). Human Parasitology, Third edition. Burlington, MA: Academic Press, 2005. 
Brooks, T.J., W.R. Webb and K.M. Heard. "Hydatid Disease: A Summary of Human Cases in Mississippi." American Medical Association Archives of Internal Medicine 104 (1959): 562-7.

Burridge, M.J. and C.W. Schwabe. 'Hydatid Disease in New Zealand: An Epidemiological Study of Transmission among Maoris'. American Journal of Tropical Medicine and Hygiene 26 (1977): 258-65.

Bynum, William. The Western Medical Tradition: 1800-2000. New York, NY: Cambridge University Press, 2006.

Cameron, Thomas W.M. "The Helminth Parasites of Animals and Human Disease." Proceedings of the Royal Society of Medicine, Section of Comparative Medicine 20 (1927): 547-56.

Catalano, Stefano et al. "Echinococcus multilocularis in Urban Coyotes, Alberta, Canada." Emerging Infectious Diseases 18 (2012): 1625-8.

Cobgill, Charles L. "Echinococcus Cyst." American Medical Association Archives of Surgery 75 (1957): 267-71.

Craig, Charles F. and Ernest Carroll Faust. Craig and Faust's Clinical Parasitology. Philadelphia: Lea \& Febiger, 1964.

“Curriculum Vitae." n.d. Calvin W. Schwabe Papers, National Library of Medicine, 1:1.

Dew, Harold. "Some Complications of Hydatid Disease." British Journal of Surgery 18 (1930): 275-93.

Dew, Harold. "Morphological Variation in Hydatid Disease." The British Journal of Surgery 45 (1958): 447-53.

"Duty Travel Report." n.d. Calvin W. Schwabe Papers, National Library of Medicine, 28:2.

Farhan, Ishak, Calvin W. Schwabe and C. Richard Zobel. "Host-Parasite Relationships in Echinococcosis: III. Relation of Environmental Oxygen Tension to the Metabolism of Hydatid Scolices." American Journal of Tropical Medicine and Hygiene 8 (1959): 473-8.

Farley, John. "The Spontaneous Generation Controversy (1700-1860): The Origin of Parasitic Worms." Journal of the History of Biology 5 (1972): 95-125.

Farley, John. "Parasites and the Germ Theory of Disease." In Framing Disease: Studies in Cultural History, edited by Charles Rosenberg and Janet Golden, 33-49. New Brunswick, NJ: Rutgers University Press, 1992.

Farley, John. Bilharzia: A History of Imperial Tropical Medicine. Cambridge: Cambridge University Press, 2003.

Joint WHO/FAO Expert Committee on Zoonoses. "Second Report." World Health Organization Technical Report Series 169 (1959): 1-83.

Joint WHO/FAO Expert Committee on Zoonoses. "Third Report." World Health Organization Technical Report Series 378 (1967): 1-127.

Jones, Wesley E., Peter M. Schantz, Kate Foreman, Linda Kay Smith, Ernest J. Witte, David E. Schooley and Dennis D. Juranek. "Human Toxocariasis in a Rural Community." American Journal of the Diseases of Children 134 (1980): 967-9. 
Jones, Susan. Death in a Small Package: A Short History of Anthrax. Baltimore: John Hopkins University Press, 2010.

Kilejian, Araxie, Lewis A. Schinazi and Calvin W. Schwabe. "Host-Parasite Relationships in Echinococcus: V. Histochemical Observations on Echinococcus Granulosus." American Journal of Tropical Medicine and Hygiene 47 (1961): 181-8.

Huxley, Thomas Henry. The Scientific Memoirs of Thomas Henry Huxley. London: Macmillan and Co., 1898.

Li, Shang-Jen. "The Nurse of Parasites: Gender Concepts in Patrick Manson's Parasitological Research." Journal of the History of Biology 37 (2004): 103-30.

Liu, Irwin K. M., Calvin W. Schwabe, Peter M. Schantz and Malcolm N. Allison. "The Occurrence of Echinococcus Granulosus in Coyotes (Canis latrans) in the Central Valley of California." Journal of Parasitology 56 (1970): 1135-7.

Mason Dentinger, Rachel. "Patterns of Infection and Patterns of Evolution: How a Malaria Parasite Brought 'Monkeys and Man' Closer Together in the 1960s." Journal of the History of Biology 49 (2016): 359-95.

Méthot, Pierre-Olivier. "Why do Parasites Harm Their Host? On the Origin and Legacy of Theobald Smith's 'Law of Declining Virulence' - 1900-1980." History and Philosophy of the Life Sciences 34 (2012): 561-601.

Mitchell, T. "Can the Mosquito Speak?" In Rule of Experts: Egypt, Technopolitics, Modernity, by T. Mitchell, 19-53. London: University of California Press, 2002.

Moro, Pedro and Peter M. Schantz. "Echinococcus: A Review." International Journal of Infectious Diseases 13 (2009): 125-33.

Nelson, George S. and Robert L. Rausch. "Echinococcus Infections in Man and Animals in Kenya." Annals of Tropical Medicine and Parasitology 57 (1963): 136-49.

Noble, Elmer R. and Glenn A. Noble. Parasitology: The Biology of Animal Parasites. Philadelphia: Lea \& Febiger, 1964.

Nolen, R. Scott. "LEGENDS: The Accidental Epidemiologist." Journal of the American Veterinary Medical Association News, 1 July 2013. Accessed April 2, 2017. https://www.avma.org/News/JAVMANews/Pages/130701m.aspx.

Packard, Randall. The Making of a Tropical Disease: A Short History of Malaria. Baltimore: Johns Hopkins University Press, 2011.

Pappanaioanou, Marguerite. "Correspondence with Calvin Schwabe." April-Jul 1977 and multiple other dates. Calvin W. Schwabe Papers, National Library of Medicine, 21:21, 21:23.

Pappanaioanou, Marguerite, Calvin W. Schwabe and Diana M. Sard. "An Evolving Pattern of Human Hydatid Disease Transmission in the United States." The American Journal of Tropical Medicine and Hygiene 26 (1977): 732-42.

Pappanaioanou, Marguerite. "Veterinary Medicine Protecting and Promoting the Public's Health and Well-Being." Preventive Veterinary Medicine 62 (2004): 153-63.

"Parasites - Echinococcosis." Centers for Disease Control, 2012. Accessed April 2, 2017. https://www.cdc.gov/parasites/echinococcosis/biology.html. 
Patterson, James T. "Disease in the History of Medicine and Public Health." In Major Problems in the History of American Medicine and Public Health: Documents and Essays, edited by John Harley Warner and Janet Tighe, 17-23. Boston: Houghton Mifflin, 2001.

Rausch, Robert. "Correspondence with Calvin W. Schwabe.” 9 January 1967. Calvin W. Schwabe Papers, National Library of Medicine, 11:10.

Rausch, Robert L. "Hydatid Disease in Boreal Regions." Arctic: Journal of the Arctic Institute of North America 5 (1952): 157-74.

Sapp, Jan. Evolution by Association: A History of Symbiosis. New York: Oxford University Press, 1994.

Schantz, Peter M. and Calvin W. Schwabe. "Worldwide Status of Hydatid Disease Control." Journal of the American Veterinary Medical Association 155 (1969): 2104-21.

Schantz, Peter M. and Cristina Colli. “Echinococcus oligarthrus (Diesing, 1863) from Geoffroy's Cat (Felis Geoffroyi D’Orbigny y Gervais) in Temperate South America." The Journal of Parasitology 59 (1973): 1138-40.

Schwabe, Calvin W. "Hoofprints of Cheiron." n.d. Calvin W. Schwabe Papers, National Library of Medicine, vol. 12.

Schwabe, Calvin W. “Correspondence with Martin Kaplan.” 3 April 1967. Calvin W. Schwabe Papers, National Library of Medicine, 9:3.

Schwabe, Calvin W. "Correspondence with Trevor Beard.” 14 July 1969, 26 Jul 1969. Calvin W. Schwabe Papers, National Library of Medicine, 5:4.

Schwabe, Calvin W. "Studies on Oxyspirura mansoni, the Tropical Eyeworm of Poultry. II. Life History.” Pacific Science 5 (1951): 18-35.

Schwabe, Calvin W. "Observations on the Respiration of Free-Living and Parasitic Nippostrongylus muris Larvae." American Journal of Hygiene 65 (1957): 325-37.

Schwabe, Calvin W. "Effects of Normal and Immune Rat Sera upon the Respiration of Free-Living and Parasitic Nippostrongylus muris Larvae." American Journal of Hygiene 65 (1957): 338-43.

Schwabe, Calvin W. "Host-Parasite Relationships in Echinococcus: I. Observations on the Permeability of the Hydatid Cyst Wall." American Journal of Tropical Medicine and Hygiene 8 (1959): 20-8.

Schwabe, Calvin W. Veterinary Medicine and Human Health. Baltimore: Williams \& Wilkins Co., 1964.

Schwabe, Calvin W., 'Curriculum Vitae', Preventive Veterinary Medicine 62 (2004): 207-216.

Schwabe, Calvin W. and Kamal Abou Daoud. "Epidemiology of Echinococcus in the Middle East I. Human Infection in Lebanon, 1949-1959." American Journal of Tropical Medicine and Hygiene 9 (1961): 374-81.

Schwabe, Calvin W., Lewis A. Schinazi and Araxie Kilejian. "Host-Parasite Relationships in Echinococcus: II. Age Resistance to Secondary Echinococcus 
in the White Mouse." The American Journal of Tropical Medicine and Hygiene 8 (1959): 29-36.

Schwabe, Calvin W., G.W. Luttermoser, M. Koussa and S.R. Ali. "Serial Passage of Fertile Hydatid Cysts of Echinococcus granulosus in Absence of the Definitive Host." Journal of Parasitology 50 (1964): 260.

Schwabe, Calvin W., Araxie Kilejian and Gerasimos Lainas. "The Propagation of Secondary Cysts of Echinococcus granulosus in the Mongolian Jird, Meriones unguiculatus." The Journal of Parasitology 56 (1970): 80-3.

Sterman, Max M. and Harold W. Brown. "Echinococcus in Man and Dog in the Same Household in New York City." Journal of the American Medical Association 169 (1959): 938-40.

Tenenbaum, Joseph. "Echinococcus Cyst of Kidney." Journal of the American Medical Association 108 (1937): 1704-5.

Turner, E.L., D.A. Berberian and E.W. Dennis. "The Production of Artificial Immunity in Dogs against Echinococcus granulosus." The Journal of Parasitology 22 (1936): 14-28.

Webster, Gloria and T.W.M. Cameron. 'Observations of Experimental Infections with Echinococcus in Rodents'. Canadian Journal of Zoology 39 (1961): 877-91.

Worboys, Michael. "The Emergence and Early Development of Parasitology." In Parasitology: A Global Perspective, edited by Kenneth S. Warren and John Z. Bowers, 1-18. New York: Springer-Verlag, 1983.

Wray, J.R. "Human Hydatid Disease in Kenya." East African Medical Journal 35 (1958): 37-9.

Open Access This chapter is licensed under the terms of the Creative Commons Attribution 4.0 International License (http://creativecommons. org/licenses/by/4.0/), which permits use, sharing, adaptation, distribution and reproduction in any medium or format, as long as you give appropriate credit to the original author(s) and the source, provide a link to the Creative Commons license and indicate if changes were made.

The images or other third party material in this chapter are included in the chapter's Creative Commons license, unless indicated otherwise in a credit line to the material. If material is not included in the chapter's Creative Commons license and your intended use is not permitted by statutory regulation or exceeds the permitted use, you will need to obtain permission directly from the copyright holder.

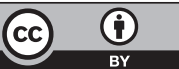

